\title{
A originalidade da obra de Georg Groddeck e algumas de suas contribuições para 0 campo da saúde*
}

Lucas Nápoli dos Santos ${ }^{1}$

André Martins ${ }^{2}$

SANTOS, L.N.; MARTINS, A. The originality of Georg Groddeck's works and some of his contributions to the field of healthcare. Interface - Comunic., Saude, Educ., v.17, n.44, p.9-21, jan./mar. 2013.

This article aimed to present some ideas about medicine, disease, health and healing extracted from the works of the physician and psychoanalyst Georg Groddeck (1866-1934). The hypothesis that guided this study was that these propositions could actively contribute towards the contemporary discussion about the limits of biomedicine and the need to reformulate the Western healthcare model. First, we analyzed the historical and philosophical origins of biomedicine and some of the dilemmas faced by users and healthcare professionals caused by the predominance of biomedical rationality. Then, some light is shed on Groddeck's life and work, culminating with presentation of four important contributions from this author, assessed in the light of the biomedical limits.

Keywords: Georg Groddeck. Disease. Health. Biomedicine.
Este artigo tem o objetivo de apresentar algumas ideias sobre medicina, doença, saúde e cura extraídas da obra do médico e psicanalista Georg Groddeck (18661934). A hipótese que norteia o trabalho é de que tais proposições podem contribuir ativamente para a discussão contemporânea sobre os limites da biomedicina e a necessidade de reformulação do modelo de cuidado em saúde ocidental. Primeiramente, são analisadas as origens históricas e filosóficas da biomedicina e alguns dos impasses enfrentados por usuários e profissionais de saúde em função do predomínio da racionalidade biomédica. Em seguida, são tecidas algumas considerações sobre a vida e a obra de Groddeck, culminando na apresentação de quatro importantes contribuições do autor avaliadas à luz dos limites biomédicos.

Palavras-chave: Georg Groddeck. Doença. Saúde. Biomedicina.

\footnotetext{
Elaborado com base em Santos (2012).

${ }^{1}$ Faculdade Pitágoras de Governador Valadares. Avenida Minas Gerais, 700, sala 711, Centro. Governador Valadares, MG, Brasil. 35.010-151. lucas.napoli@ig.com.br ${ }_{2}$ Programa de Pós-Graduação em Saúde Coletiva, Universidade Federal do Rio de Janeiro.
} 


\section{Introdução}

Recentemente, tem sido possível encontrar um número expressivo de trabalhos na literatura do campo da saúde que se dedicam a apontar as limitações do que tem sido chamado de biomedicina ou modelo biomédico. Uma amostra ilustrativa dessa produção bibliográfica é constituída por: Queiroz (1986), Camargo Júnior (1997), Bonet (1999), Caprara e Franco (1999), Martins (2004; 1999), Ayres (2001), Barros (2002), Caprara e Rodrigues (2004), Wade e Halligan (2004), Guedes, Nogueira e Camargo Júnior (2009, 2008, 2006) e Tesser (2009; 2007; 2006a; 2006b). É possível notar, nesses trabalhos, certo consenso de que o modelo biomédico precisa ser modificado, na medida em que as ações de assistência à saúde que dele decorrem têm provocado muito mais efeitos deletérios do que vantajosos tanto para os usuários dos serviços de saúde quanto para os próprios profissionais.

Podemos caracterizar como biomedicina o conjunto de diretrizes teóricas e práticas que orientam a formação médica moderna no ocidente e que, por conseguinte, guiam a prática não só dos médicos, mas, também, da maior parte dos profissionais de saúde.

No que concerne às origens históricas e conceituais da biomedicina, pode-se dizer que ela foi gestada a partir dos princípios teórico-metodológicos que fundamentaram a chamada racionalidade científica moderna (Martins, 1999; Luz, 1988; Camargo Júnior, 1997).

É precisamente a tese de que há uma separação radical entre homem e natureza, e seus postulados correlatos, que estão no fundamento da racionalidade científica moderna e, por conseguinte, também da biomedicina. Essa separação é feita no plano conceitual a fim de sustentar ideologicamente a legitimidade de um objetivo de ordem prática: o controle absoluto da natureza. Em outras palavras, só é possível pensar como viável e lícito o desejo de estabelecer domínio sobre a natureza negando-se deliberadamente o fato de que o homem está essencialmente inserido nela (Martins 1999; 2009).

A racionalidade científica moderna está calcada, portanto, no pressuposto de que não apenas é desejável como, também, possível controlar absolutamente a natureza. Possível na medida em que a razão humana, pela via da ciência, seria capaz de refletir a verdade da natureza. Os métodos e conceitos utilizados pela ciência não seriam apenas suportes capazes de auxiliar-nos a alcançar o conhecimento da realidade, mas verdadeiros espelhos da natureza. Trata-se, como hoje nos parece evidente, de uma concepção reducionista que advoga que toda a complexidade existente na natureza é passível de ser reduzida aos modelos de compreensão elaborados pela ciência (Martins, 2009; 1999).

O reducionismo que, é bom que se diga, não é um atributo da ciência, mas do cientificismo, isto é, de uma ideologia científica destinada a justificar a pretensão de controle absoluto da natureza (Martins, 2009), é um traço que se encontra presente com bastante força na biomedicina. Afinal, uma característica marcante dessa racionalidade médica é o repúdio a outros tipos de abordagem dos processos saúde-doença, por considerá-los falsos na medida em que não estão fundamentados em pesquisas com o uso dos métodos tradicionais da ciência positivista.

Outra característica da biomedicina que demonstra quanto a ideologia cientificista se faz presente nessa racionalidade é a sustentação da tese de que a medicina, para ser considerada uma prática legítima, deve, necessariamente, ser concebida como uma ciência, e não como uma arte ou uma práxis. Afinal, para a racionalidade científica moderna, o único conhecimento válido é o saber do universal, e não do particular; as únicas conclusões verdadeiras seriam as que pudessem ser generalizadas para todos os elementos de um mesmo universo (Martins, 1999).

Quando essa ideia é levada para o campo da saúde, ela coloca em jogo sérios impasses, pois conquanto seja possível estabelecer, no plano da teoria, uma ciência das doenças, concebendo as enfermidades como entidades patológicas organizadas em famílias e gêneros, na dimensão prática essa sistematização se revela absolutamente estéril. Não obstante, ainda que nem sempre isso ocorra na prática, a pretensão da biomedicina é justamente essa: estabelecer protocolos padrões para o tratamento de cada tipo de enfermidade.

Como mencionamos anteriormente, na biomedicina, as doenças não são consideradas como processos ou experiências, mas, sim, como entidades patológicas (Camargo Júnior, 1997). Ao conceber a patologia dessa forma, a biomedicina acaba promovendo uma separação entre a doença e a história de 
vida do paciente. Privilegia-se a chamada história natural da doença, a qual é justamente uma tentativa de estabelecer um conhecimento universal sobre a enfermidade.

A história natural da doença consiste em um modelo teórico proposto por Leavell e Clark, que pretende dar conta de todos os processos que se manifestam ao longo da trajetória de uma doença, indo desde as condições ambientais responsáveis pelo surgimento da patologia, passando pelos períodos de agravamento e convalescença, e desembocando nos destinos finais do processo de adoecimento que, de acordo com o modelo, podem ser: a recuperação, a cronificação da doença, a invalidez ou a morte (Leavell, Clark, 1976).

Essa concepção, que vê a doença como entidade dissociada da biografia individual, está intimamente associada com outro aspecto da biomedicina, que é a exclusão da subjetividade na análise dos processos saúde-doença (Guedes, Nogueira, Camargo Júnior, 2006).

Com o termo "subjetividade" não estamos fazendo referência apenas aos chamados fenômenos psicológicos ou variáveis emocionais. Aqui, entendemos subjetividade como o conjunto de processos afetivos, psicológicos, sociais, históricos, políticos que interagem entre si tendo um ponto comum: uma pessoa, um sujeito que, embora seja propriamente constituído por tais processos, é capaz de reagir a eles, dar-lhes sentido e organizá-los na forma de uma história de vida. É toda essa complexidade que é sistematicamente escamoteada pelo modelo biomédico, na medida em que o adoecimento é pensado como um evento apenas orgânico ou, no máximo, como uma disfunção corporal influenciada por fatores "emocionais", os quais, em última instância, podem ser reduzidos a variáveis orgânicas.

Essa ênfase nos índices e sinais orgânicos da doença caracteriza o que nos autorizamos a assinalar como o reducionismo por excelência da biomedicina: o reducionismo organicista.

Trata-se de um ponto de vista sobre a doença profundamente influenciado pela criação, em meados do século XIX, da disciplina anatomia patológica, que se distinguia por estudos comparativos entre a evolução e os sintomas das enfermidades e lesões encontradas no corpo do doente. O advento da anatomia patológica operou uma transformação radical na compreensão da doença. Se anteriormente a medicina das espécies destacava os sintomas como os signos suficientes para determinar qual entidade patológica estava em jogo e a qual família e gênero ela estaria vinculada, com a entrada em cena dos dados anatômicos, o corpo passa a ser tomado como a sede onde se encontra a verdade da doença (Foucault, 2008).

Posteriormente, com a invenção dos diversos métodos de exame por imagem, o sentido da visão ganharia ainda mais prestígio no campo da saúde. Por conta disso, o discurso do doente passaria a ter um valor bastante reduzido no modelo biomédico. O que geralmente se leva em conta como fundamento para a elaboração do diagnóstico é aquilo que os exames são capazes de evidenciar. Nesse sentido, os dados anatomofisiológicos acabam funcionando como os únicos critérios definitivos para determinar não apenas o diagnóstico, mas, até mesmo, se o indivíduo está de fato doente.

Diante desse panorama de problemas, impasses e limitações do paradigma biomédico, consideramos que não é suficiente apenas indicar e defender a necessidade de transformação. É preciso, efetivamente, apontar possíveis soluções ou, no mínimo, propostas que sejam capazes de contribuir para a elaboração de um novo paradigma para o cuidado em saúde. Nossa hipótese aqui é a de que, na obra do médico e psicanalista Georg Groddeck (1866-1934), é possível encontrar contribuições dessa natureza. Contudo, antes de analisarmos quais seriam tais proposições, falemos um pouco acerca do autor.

\section{Quem foi Georg Groddeck?}

Georg Walther Groddeck nasceu em 13 de outubro de 1866, na cidade alemã de Bad Kösen. Por influência do pai, que também era médico, e por contingências de sua vida infantil, Groddeck seguiria a carreira médica, especializando-se no tratamento de doenças crônicas. Em 1900, funda um sanatório na cidade de Baden-Baden, onde trabalharia até o fim da vida.

Groddeck fica relativamente conhecido no meio médico e psicanalítico a partir do final da década de 1910, quando inicia sua correspondência com Sigmund Freud e adere ao movimento psicanalítico. Quatro anos antes de escrever sua primeira carta a Freud, Groddeck havia publicado o livro 
"NASAMECU", título formado a partir das sílabas iniciais do ditado latino "Natura sanat medicus curat" ("A natureza cura, o médico trata"), adágio defendido como princípio de prática médica por seu mestre em medicina, Ernst Schweninger. Nesse livro, que é uma espécie de tratado geral sobre medicina para uso leigo, Groddeck tece agudas críticas à psicanálise sem verdadeiramente, no entanto, ter lido os textos de Freud.

Reconhecendo tal injustiça, na primeira carta ao pai da psicanálise, Groddeck relata as descobertas a que teve acesso no tratamento de pacientes com doenças orgânicas, achados que são bastante semelhantes aos que o próprio Freud obtivera a partir do tratamento da neurose. Com efeito, Groddeck notara que os sintomas de seus pacientes podiam ser lidos e interpretados como símbolos de uma dinâmica subjetiva. Ora, Freud tivera contato com experiência análoga. A diferença estava no fato de que os pacientes que Groddeck atendia sofriam de patologias somáticas, e não psíquicas como a histeria, a fobia e a neurose obsessiva - quadros clínicos mais frequentes na clínica freudiana (Groddeck, 1994).

A novidade trazida por Groddeck a Freud era, portanto, a extensão da psicanálise para outros territórios além da neurose. De fato, como atestam os inúmeros exemplos relatados por Groddeck em suas cartas a Freud e em seus artigos, o médico de Baden-Baden obtinha êxito no tratamento de seus pacientes utilizando o método psicanalítico. Freud manifestara-se explicitamente entusiasmado com as pesquisas de Groddeck e lhe autorizara a considerar-se psicanalista, criticando apenas o ponto de vista filosófico de Groddeck a respeito das relações entre corpo e mente. Com efeito, Groddeck afirmara, na primeira carta, que não considerava que haveria uma separação entre corpo e psiquismo, mas que ambos seriam facetas de um mesmo todo. Freud considerara tal concepção um tanto quanto carregada de misticismo (Groddeck, 1994).

Ao propor a aplicação da psicanálise no tratamento de doenças orgânicas e o entendimento simbólico dos sintomas somáticos, Groddeck passou a ser considerado como um dos fundadores da chamada "medicina psicossomática", embora o próprio autor tenha se esquivado de tal epíteto argumentando que, do seu ponto de vista, não haveria "psicogênese", ou seja, não se trataria de pensar a doença orgânica como sendo causada por elementos de ordem psicológica. Para Groddeck, não haveria a ação de uma instância sobre a outra. Ambos, psiquismo e corpo se enfermariam ao mesmo tempo, e é essa condição que permitiria que o adoecimento pudesse ser lido simbolicamente: o fato de que qualquer doença estaria inevitavelmente conectada à vida como um todo.

Outro ponto que levou Groddeck a adquirir algum destaque no campo psicanalítico foi o fato de ter sido o criador do conceito de Isso (em alemão: das Es), que Freud passaria a utilizar a partir do início da década de 1920 em sua segunda tópica. Embora o próprio Freud tivesse indicado brevemente, em "O Ego e o Id", obra em que introduz os elementos da segunda tópica, que passara a utilizar o conceito por influência de Groddeck, ainda há muitos analistas que ignoram a precedência do médico de Baden-Baden quanto ao uso do termo ${ }^{3}$.

Apesar de Freud ter sido influenciado por Groddeck na adoção do termo "das Es", o "id" freudiano é essencialmente distinto do "Isso" groddeckiano. Enquanto Freud caracteriza o primeiro como a parte mais primitiva do aparelho psíquico, sede das pulsões, o conceito de Isso em Groddeck recebe uma caracterização muito mais ampla. Groddeck utiliza o termo "Isso" como um conceito capaz de abarcar tanto a força impessoal, que não conhece fronteiras espaço-temporais e que produz o indivíduo, quanto o próprio indivíduo em sua constituição psicossomática.

Atualmente, não são muitos os artigos que se dedicam a explorar exclusivamente o pensamento groddeckiano, sobretudo no Brasil. Em 1995, Elida
${ }^{3}$ O termo "das Es" designa, na língua alemã, um pronome impessoal. A "Edição Standard das Obras Psicológicas

Completas de Sigmund Freud" traduziu o termo pelo vocábulo latino equivalente: "id". Não obstante, em todas as traduções dos textos de Groddeck publicadas no Brasil, utiliza-se o termo Isso em vez de id. Do nosso ponto de vista, tal opção é a mais adequada, pois, além de ser uma tradução direta do alemão para o

português, as associações semânticas do termo Isso tendem a levar às ideias de algo indiferenciado, enigmático, desconhecido, justamente alguns dos atributos com os quais Groddeck caracteriza o conceito. 
Singelmann cotejou os pensamentos de Groddeck e Freud, demonstrando as divergências epistemológicas entre os dois autores e apontando a maior proximidade das ideias de Groddeck em relação ao modelo contemporâneo de ciência, marcado, segundo a autora, pela teoria da complexidade (Singelmann, 1995).

Entre o final da década de 1990 e o início dos anos 2000, Lazslo Antônio Ávila publicou uma série de trabalhos que abordavam especificamente a obra de Georg Groddeck. Em tais escritos, Ávila comentou a obra-prima do autor, "O Livro dlsso" (Ávila, 1998); fez uma comparação entre o conceito de Isso em Groddeck e a noção de inconsciente em Freud (Ávila, 1999); demonstrou a relevância dos pontos de vista do autor para a psicossomática psicanalítica (Ávila, 2002); e fez uma espécie de "vida e obra" do autor em um artigo escrito em língua inglesa (Ávila 2003). Recentemente, em 2011, Ávila publicou um novo artigo em língua inglesa em que avalia os resultados de algumas intervenções no campo da saúde baseadas nas ideias de Groddeck (Ávila, 2011). Nesse trabalho, Ávila analisa a eficácia de uma abordagem groddeckiana em dois casos clínicos de pacientes com padecimentos orgânicos. Em ambos os casos, Ávila demonstra a necessária articulação entre os sintomas orgânicos e aspectos da subjetividade e, em decorrência, a insuficiência de uma terapêutica estritamente centrada na fisiopatologia e que não contempla fatores como a transferência na relação médico-paciente, bem como o significado e os usos que o paciente pode vir a fazer da doença em sua história de vida. Podemos considerar que, nesse artigo, Ávila fornece sustentação empírica para os postulados groddeckianos que serão objeto de discussão neste trabalho.

É possível, também, encontrar trabalhos que, embora não tenham a obra de Groddeck como temática central, fazem algumas referências mais ou menos detalhadas ao pensamento do autor. Souza (1997) utilizou o ponto de vista de Groddeck em relação às doenças para sustentar sua tese de que o aparelho psíquico freudiano seria, de fato, um aparelho psicossomático. Birman (2003), em um artigo em que discutiu a frequência com que sintomas corporais têm-se feito presentes na clínica contemporânea, reconheceu o pioneirismo de Groddeck na aplicação da psicanálise às doenças orgânicas. Casetto (2006), ao traçar uma visão em perspectiva da psicossomática psicanalítica, abordou de maneira sucinta as ideias de Groddeck, comparando-as com o ponto de vista de outros autores. Já Castro, Andrade e Müller (2006) mencionaram o nome de Groddeck em alguns momentos de um trabalho dedicado à análise da evolução histórica dos conceitos de saúde/doença e da dicotomia mente/corpo. Cruz e Pereira Júnior (2011), em uma revisão das principais abordagens teóricas em Psicossomática, fizeram referência à concepção de Groddeck acerca das doenças, fornecendo, contudo, uma caracterização um tanto esquemática e superficial dos pontos de vista do autor.

É possível observar, a partir desse breve apanhado da literatura, que o pensamento groddeckiano tem sido utilizado crescentemente na composição de trabalhos cujo foco central recai sobre temas como psicossomática, clínica contemporânea e relação mente-corpo. Constata-se, contudo, que ainda há muito o que desenvolver a respeito dos estudos groddeckianos, seus conceitos e sua relevância para a área da saúde contemporânea.

Já a pouca atenção dada à obra do autor por parte dos meios médico e psicanalítico pode estar associada ao fato de Groddeck não ter efetivamente feito parte da comunidade psicanalítica. A originalidade e o desejo do autor de se diferenciar fizeram com que ele não se preocupasse em seguir a ortodoxia psicanalítica. Para Groddeck, a psicanálise era apenas mais um recurso a ser agregado a seu material terapêutico. Renunciando, portanto, ao destaque no interior do território psicanalítico, o médico se contentava em publicar a maior parte de seus artigos no periódico "Die Arche" (A Arca), que circulava apenas entre seus pacientes no sanatório.

\section{O doente, e não a doença, é o verdadeiro objeto do tratamento médico}

Fizemos referência, anteriormente, ao fato de que, no paradigma biomédico, a medicina é vista como ciência e, por conta disso, a doença adquire preeminência em relação ao doente ao olhar do profissional de saúde. Afinal, se se trata de uma atividade científica, tal como a concebe a racionalidade científica moderna, é preciso reduzir a complexidade da experiência do doente à forma límpida da classificação nosológica: 
[...] a pessoa doente, traduzida no modo de pensar científico, metamorfoseia-se na doença. Há aí um sutil e importante processo, ao mesmo tempo epistemológico e de crucial importância ética: a tradução científica da pessoa doente a transforma em alguém portador de uma doença, para, em seguida, começar a desfocar da primeira (a pessoa) para focalizar na segunda (a doença), que cresce em importância e ameaça monopolizar a atenção, como objeto do trabalho médico. (Tesser, 2007, p.468)

Mesmo antes de conhecer a psicanálise, quando ainda escrevia apenas sobre medicina, Groddeck já se posicionava veementemente contra a tendência, que já era possível ser encontrada entre seus colegas de profissão, de ênfase na doença, e não no doente. Groddeck argumenta, seguindo as consequências dessa asserção, que a tendência a valorizar o que o paciente tem, e não como o paciente está, faz do profissional de saúde um especialista na descrição de sintomatologias e quadros clínicos, mas não alguém que, de fato, é capaz de ajudar a restauração da força do enfermo - a verdadeira função da atividade médica para o autor. Numa carta escrita a um professor de medicina de Berlim, por volta de 1895, Groddeck localiza esse problema como tendo origem na formação médica:

A ciência que lá [na Universidade] se ensina não conhece doentes, somente grupos de doenças. Não conhece o indivíduo, conhece apenas casos. Não sabe nada de diagnóstico pessoal, ensina o diagnóstico em palavras, nomes de doenças. Nada suspeita de tratamento individualizador do ser humano, mas ensina o remédio contra as doenças. Ela ensina erudição, mas nenhum saber-fazer. (Groddeck, 1994, p.98)

Note-se que Groddeck está fazendo referência, nessa citação, à formação médica de sua época (final do século XIX), quando a medicina ainda não contava com todo o aparato tecnológico que, hoje, está disponível. Hoje, essa situação se intensificou, na medida em que, atualmente, se pode contar com métodos mais eficazes de investigação de agentes patológicos e da própria expressão da doença no corpo.

Para Groddeck, a única forma de dirimir os problemas oriundos da supervalorização da doença em detrimento do doente é a inversão dos polos: é preciso que o conhecimento da doença e o diagnóstico se tornem procedimentos meramente complementares à tarefa primordial do profissional de saúde, que é a de ajudar. Trata-se, em última instância, de repensar a legitimidade de se considerar a medicina como uma ciência das doenças, e não como uma arte de curar.

\section{Por um diagnóstico do ser humano}

Frequentemente, na prática, a elaboração correta do diagnóstico constitui-se na atividade central do médico, de tal modo que, frente a quadros clínicos de difícil ou impossível classificação, o profissional de saúde, simplesmente, não sabe o que fazer. Isso ocorre porque os protocolos terapêuticos estão diretamente associados às classificações nosológicas, fazendo com que o médico só saiba o que fazer caso consiga encaixar as manifestações do doente numa categoria patológica específica.

Groddeck, por seu turno, considera o diagnóstico um procedimento não apenas dispensável em alguns casos, como, também, amiúde, danoso para o doente e para o tratamento. Seu argumento repousa na tese de que, tendo em vista as pretensões, daquele que elabora o diagnóstico, de identificar a doença, trata-se, nesse processo, de uma espécie de violação da realidade. Ao primar pela identificação da entidade patológica da qual o indivíduo padeceria, aquele que diagnostica é forçado a excluir do seu campo de visão toda a complexidade do real da qual a patologia é apenas um fragmento:

Não é possível estabelecer um diagnóstico completo, que esgote todos os aspectos, e só o desejo de fazê-lo já implica o maior risco que o médico corre, o de superestimar sua capacidade. Insistimos em dizer que o diagnóstico sempre deve ser questionado pelo médico, que este nunca deve se esquecer de que muitas vezes o diagnóstico é insuficiente ou errado, e que ao estabelecê-lo corre o risco de considerar a doença como uma situação, quando na verdade ela é um processo. (Groddeck, 1992, p.247) 
Groddeck, portanto, não nega a relevância ou a utilidade do diagnóstico; só diz que o diagnóstico cujo foco é exclusivamente o reconhecimento da doença consiste num procedimento assaz equivocado, na medida em que não contempla aspectos de suma importância para o tratamento, como, por exemplo: o modo como doente e médico se relacionam, a forma como o paciente formula sua demanda de cura, entender a função da doença para aquele paciente etc. Nesse sentido, considerando que é impossível tratar um paciente sem algum tipo de diagnóstico, Groddeck irá propor que, em vez do diagnóstico tradicional da medicina, isto é, o diagnóstico que visa à classificação do sofrimento do paciente em alguma categoria nosológica, se faça um diagnóstico do ser humano. Trata-se de um diagnóstico que não contém dados relativos apenas a sinais e sintomas, mas, o máximo possível, de variáveis sobre o paciente, como aspectos psicológicos, sociais e relativos a sua história de vida.

O diagnóstico do ser humano também está fundamentado na tese groddeckiana de que o médico deve tratar o ser humano, e não o doente. Ao se concentrar no fato de que aquele que o procura está doente, os médicos automaticamente reduzem ainda mais sua percepção para se dirigirem apenas àquilo que, no discurso do indivíduo, tem relação imediata com a doença. Assim, o profissional exclui do seu campo de observação toda a imensidão de fatores que está por trás do estar doente e dos quais esse estado é a expressão. Groddeck propõe, então, que o médico deva fornecer ajuda ao ser humano que a ele recorre, e não ao estado doentio em que ele se encontra.

Se entendermos a doença na perspectiva groddeckiana, isto é, como uma expressão do Isso, quando se elimina somente o estar doente e deixa-se intacto o ser humano, o indivíduo perde, justamente, o único modo possível que havia encontrado até então para se expressar. Em decorrência, na falta daquele, talvez passe a se expressar através de outro até mais grave...

Para diagnosticar o ser humano, segundo Groddeck, para além do estar doente, em primeiro lugar, o médico não deve limitar seu olhar ao corpo; deve realizar um estudo completo do indivíduo, atentando para o que ele tem de comum em relação a outros e o que lhe é singular. O profissional deve examinar "sua figura e a forma dos seus órgãos e partes, internos e externos, suas funções desde respirar, dormir, movimentar-se, digerir, pulsar o coração até falar, pensar, sentir" (Groddeck, 1994, p.258). Em segundo lugar, o médico deve considerar tudo o que o indivíduo sente e faz, voluntária ou involuntariamente, como sintomas. Do ponto de vista de Groddeck, sintomas não significam apenas indícios da existência de uma doença, mas, sim, linguagens que o Isso utiliza para se expressar:

[...] no conceito de sintoma não estão incluídos apenas a temperatura, a pulsação e os diversos sinais de doença, mas tudo o que o isso do doente mostra e o que o isso do médico é capaz de perceber, da forma do queixo às comoções profundamente secretas, das presentes situações ao passado mais longínquo. (Groddeck, 1994, p.228)

Para Groddeck, saúde e doença não são estados individuais completamente distintos, pois ambos são formas de expressão do indivíduo, do Isso. A questão mais importante, portanto, para o profissional de saúde, não é a eliminação da doença, mas, sim, a compreensão acerca das razões pelas quais o indivíduo está se expressando de modo patológico. Para esse discernimento, não é suficiente um diagnóstico que tenha como foco os caracteres particulares da doença que se supõe habitar o corpo do doente. Será preciso considerar toda e qualquer manifestação do indivíduo como um índice para o entendimento de sua condição. Tudo aquilo que ele faz será visto como sintoma não da doença, mas do ser humano, do indivíduo que ele é e que, naquele momento específico, está se expressando pela via da doença. No texto "Da visão, do mundo dos olhos e da visão sem os olhos", no qual Groddeck faz uma longa interpretação do significado simbólico dos órgãos visuais, o autor aborda a importância do diagnóstico amplo do ser humano como ferramenta essencial para o êxito do tratamento:

Para o juízo médico e humano é muito significativo se a pessoa que sofre de algum mal da visão é um homem, uma mulher, uma criança ou um ancião, como também é importante saber quais são as condições de vida do paciente, quais são seus desejos e necessidades, como é o seu caráter, suas características pessoais, como é a sua constituição, e tudo que se possa descobrir sobre sua pessoa, seu consciente e seu inconsciente, para tratá-lo de forma 
adequada. Uma parte dos enfermos que oferece resistência a um tratamento baseado num diagnóstico anatômico irá melhorar ao se ampliar a maneira de diagnosticar. (Groddeck, 1992, p.249)

\section{Compreensão, e não combate à doença}

Herdeiro da racionalidade científica moderna, o modelo biomédico concebeu as relações entre a medicina e a doença analogamente àquelas estabelecidas entre razão e natureza. As doenças passaram, então, a ser pensadas como seres provenientes da perigosa natureza, e que deveriam, portanto, ser combatidos e extirpados.

As doenças, legitimadas e objetivadas pela construção científica das entidades nosológicas (e dos riscos), converteram-se em inimigos naturais e, como se tivessem vida própria, parecem estar, a cada paciente, sintoma e/ou exame, prestes a atacar (Tesser, 2009, p.279).

A ideia de que a doença seria um mal proveniente da natureza, que, por colocar a frágil saúde humana em risco, precisaria ser eliminado, deu ensejo, na biomedicina, ao que Tesser chama de "obsessão pelo controle" (Tesser, 2009, p.278). Trata-se da tendência de considerar o cuidado em saúde não apenas como salvador do homem já invadido pela patologia, mas, também, como o protetor dos indivíduos, que os impediria de ficarem doentes. Tesser (2009) mostra que o controle é também um traço que a biomedicina herdou da racionalidade científica moderna. Com efeito, a ciência moderna se concebe como destinada a controlar e prever fenômenos. Assim, a medicina teria a função não apenas de combater e eliminar as doenças já manifestas, mas de controlar determinados aspectos do indivíduo de modo a impedir o aparecimento da doença. A noção de "fator de risco" como condição que estatisticamente está associada a determinado tipo de doença contribui para que a obsessão pelo controle seja assumida como postura não só pela medicina, como, também, pelos próprios usuários dos serviços de saúde. Assim, em nome de se evitarem riscos supostos, a medicina preconizará intervenções cirúrgicas ou medicamentosas, mesmo que estas provoquem reações adversas e efeitos colaterais por vezes incapacitantes, tornando-se, nestes casos, iatrogênica, causando novas enfermidades no paciente em prol do combate a supostas complicações futuras.

Qual alternativa Groddeck propõe como contraponto à postura beligerante da biomedicina? Trata-se de sua concepção da doença como um fenômeno de expressão do indivíduo, tal como o caminhar, o comer, o beber, o pensar etc. Não obstante, a enfermidade é um tipo de expressão que o organismo só utiliza quando as vias saudáveis através das quais poderia se manifestar encontram-se indisponíveis. Em outras palavras, a doença é o último recurso empregado pelo Isso para se expressar. Ela é sempre um estado de exceção. Nesse sentido, se o profissional de saúde guia sua atuação clínica a partir da tese de que a doença é apenas um mal que faz o indivíduo sofrer e que deve, portanto, ser extirpada para dar lugar à saúde, do ponto de vista groddeckiano ele estaria prejudicando ainda mais o paciente, pois estaria eliminando a única via que esse encontrara até então para se revelar.

A retirada forçada de uma lesão que acompanha determinado doente há 40 anos não significará simplesmente a remoção de um sintoma que debilitava o sujeito. A intervenção incidirá no nível da própria identidade do sujeito, que fora organizada, ao longo daqueles quarenta anos, tendo a lesão como um elemento constante e fixo. A atitude beligerante não leva em conta, por conseguinte, a função que a enfermidade exerce na vida do doente:

[...] acredito que seria bem melhor abandonar de vez a ideia do combate e convencer-se de que é mais aconselhável para o doente, o médico e as pessoas da nossa cultura, conceber a doença como uma providência necessária do Isso, oportunamente introduzida com finalidades determinadas e que decerto pode ser nociva para o ser humano como um todo. (Groddeck, 1992, p.136) 
Groddeck propõe, então, que a doença não seja propriamente combatida, mas compreendida. Se o Isso só recorre à linguagem da doença quando a da saúde está inviabilizada, logo é preciso compreender por que essa situação está acontecendo. Em outras palavras, as principais questões que o médico deve se fazer perante o doente são: por que esse indivíduo está precisando dessa doença? O que o impede de se expressar por vias não dolorosas, saudáveis?

Groddeck acredita que, espontaneamente, o indivíduo tenda a se expressar por vias salutares, de modo que a doença pode ser vista como a consequência de um bloqueio dessa espontaneidade em função de alguma contingência: "Portanto, pode-se admitir que o Isso não recorra de bom grado ao recurso excepcional da doença, procurando retornar o mais breve possível às suas formas habituais de expressão na vida saudável" (Groddeck, 1992, p.103). O médico deve, portanto, buscar discernir as razões que levaram o indivíduo a recorrer à doença, um procedimento que Groddeck costumava chamar de "interrogar o Isso" (Groddeck, 2008, p.97) e que, na prática, diz respeito à observação criteriosa e a uma escuta atenta e acolhedora que não fique restrita àquilo que o paciente relata acerca do que vem sentindo corporalmente, mas que o convoque a falar de si da maneira mais abrangente possível.

Compreender e ajudar o paciente a discernir os obstáculos que o impediam de se manifestar por vias saudáveis, obrigando-o a recorrer às veredas dolorosas da doença, é o que cabe ao médico, não buscar a eliminação da doença a qualquer custo. Para Groddeck, uma extirpação pura e simples da enfermidade pode resultar, de fato, no seu desaparecimento. Não obstante, não se pode considerar que o doente tenha sido verdadeiramente tratado, pois não se tocou na função que a doença desempenhava, ou seja, a ação de saúde não interveio sobre a gênese do problema, mas apenas sobre sua superfície:

É claro que, na maioria das vezes, o caminho mais curto e mais fácil para ajudar é atacar a sua doença, mas não deve ser dessa forma; pois a doença é apenas uma forma de expressão do isso sofredor, que acentua em voz alta a sua doença, a fim de ocultar melhor ainda o seu segredo mais profundo. (Groddeck, 1994, p.258)

Depois de "interrogar o Isso" e descobrir as motivações que o levaram a se refugiar na doença, trata-se, agora, de estabelecer um processo de convencimento do Isso. É preciso convencê-lo de que os perigos aos quais se julgara exposto e que estavam impedindo-o de falar a linguagem da saúde, ao serem compreendidos, perderam a sua força destrutiva, de modo que a doença pode ser abandonada: "Cabe primeiramente provar ao Isso doente e teimoso que ele pode sair-se bem novamente, recorrendo às suas formas salutares de expressão" (Groddeck, 1992, p.104).

\section{Corpo e psiquismo como dialetos do Isso}

Um dos traços mais marcantes da racionalidade científica moderna é a enunciação de uma série de dicotomias, como natureza/cultura, indivíduo/sociedade, e a que mais nos interessa nesse momento: corpo/mente, separação que, embora já estivesse presente no pensamento dos filósofos gregos posteriores a Sócrates, e tivesse atravessado toda a filosofia medieval, encontrou, no pensamento do filósofo francês René Descartes, sua versão mais explícita, e, por ser elaborada nos moldes da modernidade nascente, mais próxima de sua influência sobre a medicina científica moderna e sobre as práticas de saúde contemporâneas. Com efeito, o pensador francês concebeu corpo e mente como duas substâncias ou, em outros termos, como duas coisas absolutamente distintas e que representavam a manifestação de dois mundos separados: o mundo das coisas extensas, materiais, e o mundo do pensamento ou das coisas imateriais (Descartes, 1996).

O modelo biomédico, na medida em que é erigido nas bases dessa racionalidade, tomará a separação entre corpo e mente quase como um dado, uma premissa, um postulado. Dessa dicotomia 
nascerá um processo de especialização e diferenciação entre dois campos: as doenças orgânicas e as doenças mentais ${ }^{4}$. Entre esses dois grandes grupos de patologias, existiria a psicossomática, um terreno nebuloso, prenhe de incoerências e contradições. Tradicionalmente, as doenças que se localizam nesse grupo compreendem enfermidades cuja forma de manifestação é orgânica, mas cuja etiologia estaria relacionada, predominantemente, a elementos psicológicos. Como vimos anteriormente, Groddeck negara-se a ser reconhecido como um dos pioneiros do campo psicossomático. São justamente as razões que o levaram a negar-se a carregar essa alcunha, as contribuições que o autor traz para as discussões sobre os impasses produzidos pela dicotomia corpo/mente no paradigma biomédico. Para Groddeck,

O corpo é algo morto, portanto não pode adoecer; nós já nos esquecemos que nossos antepassados, em vez da palavra corpo (Körper), usavam a expressão cadáver (Lichnam), como os holandeses ainda utilizam, assim como os ingleses só usam a palavra corps no sentido de cadáver. Não sei se existe uma alma, uma psique independente e imaterial, ainda não travei conhecimento com um ser dessa natureza. Mas nem todos os que estão convencidos da existência de um mundo dos espíritos são loucos. Talvez haja algo semelhante. Mas com toda a certeza esses espíritos, se existirem, não podem ficar doentes no nosso sentido humano, pois para tanto é preciso o corpo. (Groddeck, 1992, p.125-126, grifos do autor)

Eis a crítica de Groddeck ao pensamento dualista, crítica que evidencia que o autor jamais concebeu as enfermidades com as quais trabalhava como afecções psicossomáticas. Partindo do argumento exposto pelo autor nessa citação, a divisão entre doenças somáticas e doenças mentais é absolutamente equivocada. Só se poderia falar de doenças exclusivamente somáticas caso fosse possível conceber um corpo sem psique que fosse capaz de adoecer. Nesse caso hipotético, sim, poder-se-ia dizer que ocorreu um adoecimento sem a participação de qualquer elemento psicológico. Não obstante, sabe-se que só um corpo vivo, ou seja, em que há a presença de uma realidade psíquica, pode, de fato, adoecer. Nesse sentido, em toda doença, haveria a participação de fatores referentes à dimensão orgânica e à dimensão psíquica do indivíduo, “[...] logo se deduz que não há 'organismo' e 'psiquismo', nem doenças físicas ou psíquicas e sim que são sempre os dois a enfermar ao mesmo tempo, em quaisquer circunstâncias" (Groddeck, 1992, p.125).

Trata-se efetivamente, no pensamento de Groddeck, de conceber corpo e psiquismo como dimensões de uma realidade única e indivisível, duas formas de abordar o Isso ou dois modos diferentes de se referir à totalidade individual. "São apenas denominações cômodas para melhor entender certas singularidades da vida; no fundo, ambas são uma mesma coisa" (Groddeck, 2008, p.111). Logo na primeira carta que envia a Freud, Groddeck já deixa claro seu posicionamento acerca dessa questão:

[...] formara-se em mim a convicção de que a distinção entre corpo e alma é apenas uma diferença de nome e não de essência; que o corpo e a alma são alguma coisa de comum, que neles habita um Isso, uma força pela qual somos vividos, enquanto nós acreditamos viver.

(Groddeck, 1994, p.5)
${ }^{4}$ É forçoso assinalar que, na atualidade, sobretudo em virtude da pesquisa neurocientífica, tem crescido a tendência, por parte de alguns pesquisadores, de reduzirem as doenças mentais ao campo das doenças orgânicas, a partir da hipótese de que o psiquismo seria apenas um epifenômeno do funcionamento cerebral. Trata-se, portanto, de uma aparente superação do dualismo, mas pela via de sua conversão a um monismo fisicalista que denega a existência da especificidade do pensamento e do psiquismo na unidade mente-corpo. 
A grande contribuição de Groddeck ao propor que corpo e psiquismo sejam vistos como duas modalidades de apresentação do Isso, e não como duas essências separadas, é a eliminação da separação estéril entre doenças orgânicas e doenças mentais: "Em outras palavras, recusei de antemão separar doenças do corpo e doenças da alma; tentei tratar o ser individual em si, o isso que existe nele; procurei um caminho que levasse ao impenetrado, ao impenetrável" (Groddeck, 1994, p.5).

Além disso, a substituição do dualismo pelo monismo levaria à extinção do campo psicossomático, na medida em que ele seria extenso a ponto de englobar toda e qualquer patologia. Em decorrência, todo profissional da saúde seria levado a tomar um ponto de vista integral sobre o doente, uma perspectiva que contemplasse a dimensão orgânica e, ao mesmo tempo, fosse capaz de uma leitura psicológica do adoecimento. De fato, é precisamente isso o que Groddeck preconiza: que todo profissional de saúde seja capaz de utilizar um método de leitura simbólica dos sintomas do doente, o que não consiste em um procedimento demorado, tampouco caro. Basta que o profissional se disponha a ouvir e a acolher o doente em sua totalidade, estando atento para perceber as vinculações entre suas queixas e sua história subjetiva.

\section{Considerações finais}

Queremos frisar que nossa proposta, aqui, não é a de que a medicina deva - para superar os impasses que vivencia em função do paradigma biomédico - adotar integralmente as teses de Georg Groddeck acerca da doença e do tratamento. Nosso interesse é o de demonstrar que as indicações desse autor fornecem aportes teóricos férteis para se pensar em possíveis soluções para aqueles problemas. Neste trabalho, apresentamos, pelo menos, quatro importantes contribuições extraídas da obra groddeckiana para um novo paradigma de cuidado em saúde:

(1) Estabelecimento do doente, e não da doença, como verdadeiro objeto das intervenções em saúde;

(2) Concepção do diagnóstico como um processo amplo de conhecimento do doente, abordando inúmeros aspectos que estão para além dos sinais e sintomas;

(3) Em vez do combate e controle da doença, a compreensão da enfermidade como linguagem, modo de manifestação que exerce uma função na história de vida do paciente;

(4) Eliminação da dicotomia entre corpo e mente e as categorias que decorrem dessa separação, a saber: doenças orgânicas, doenças mentais e doenças psicossomáticas; concepção das dimensões orgânica e psíquica como formas de expressão individual, e não como duas substâncias.

\section{Colaboradores}

Os autores trabalharam juntos em todas as etapas de produção do manuscrito. 


\section{Referências}

ÁVILA, L.A. Groddeckian interventions in medical settings. Am. J. Psychoanal., v.71, n.3, p.278-89, 2011.

Georg Groddeck: originality and exclusion. Hist. Psychiatr., v.14, n.1, p.83-101, 2003.

Doenças do corpo e doenças da alma. São Paulo: Escuta, 2002.

O telescópio e o caleidoscópio: o inconsciente em Freud e Groddeck. Psicol. USP, v.10, n.1, p.157-68, 1999.

Isso é Groddeck. São Paulo: EDUSP, 1998.

AYRES, J.R.C.M. Sujeito, intersubjetividade e práticas de saúde. Cienc. Saude Colet., v.6, n.1, p.63-72, 2001.

BARROS, J.A.C. Pensando o processo saúde doença: a que responde o modelo biomédico? Saude Soc., v.11, n.1, p.67-84, 2002.

BIRMAN, J. Corpo e formas de subjetivação em psicanálise. 2003. Disponível em: <http://egp.dreamhosters.com/encontros/mundial_rj/download/

3_Birman_38020903_port.pdf>. Acesso em: 25 out. 2012

BONET, O. Saber e sentir: uma etnografia da aprendizagem da biomedicina. Physis, v.9, n.1, p.123-50, 1999.

CAMARGO JÚNIOR, K.R.D. A biomedicina. Physis, v.15, n.1, p.45-68, 1997.

CAPRARA, A.; FRANCO, A.L.E.S. A relação paciente-médico: para uma humanização da prática médica. Cad. Saude Publica, v.15, n.3, p.647-54, 1999.

CAPRARA, A.; RODRIGUES, J. A relação assimétrica médico-paciente: repensando o vínculo terapêutico. Cienc. Saude Colet., v.9, n.1, p.139-46, 2004.

CASETTO, S.J. Sobre a importância de adoecer: uma visão em perspectiva da psicossomática psicanalítica no século XX. Psychê, v.10, n.17, p.121-42, 2006.

CASTRO, M.G.; ANDRADE, T.M.R.; MULLER, M.C. Conceito mente e corpo através da história. Psicol. Est., v.11, n.1, p.39-43, 2006.

CRUZ, M.Z.; PEREIRA JÚNIOR, A. Corpo, mente, emoções: referenciais teóricos da psicossomática. Rev. Simbio-Logias, v.4, n.6, p.46-66, 2011

DESCARTES, R. Discurso do método. São Paulo: Martins Fontes, 1996.

FOUCAULT, M. O nascimento da clínica. 6.ed. Rio de Janeiro: Forense Universitária, 2008.

GRODDECK, G. O livro dlsso. São Paulo: Perspectiva, 2008.

O homem e seu isso. São Paulo: Perspectiva, 1994.

Estudos psicanalíticos sobre psicossomática. São Paulo: Perspectiva, 1992.

GUEDES, C.R.; NOGUEIRA, M.I.; CAMARGO JÚNIOR, K.R.D. Os sofredores de sintomas indefinidos: um desafio para a atenção médica? Physis, v.19, n.3, p.797-815, 2009.

Os sintomas vagos e difusos em biomedicina: uma revisão da literatura. Cienc. Saude Colet., v.13, n.1, p.135-44, 2008.

A subjetividade como anomalia: contribuições epistemológicas para a crítica do modelo biomédico. Cienc. Saude Colet., v.11, n.4, p.1093-103, 2006.

LEAVELL, H.; CLARK, E.G. Medicina preventiva. São Paulo: McGraw-Hill do Brasil, 1976.

LUZ, M. Natural, racional, social: razão médica e racionalidade científica moderna. Rio de Janeiro: Campus, 1988. 
MARTINS, A. Multi, inter e transdisciplinaridade sob um olhar filosófico. In: VEIT, M.T. (Org.). Transdisciplinaridade em oncologia: caminhos para um atendimento integrado. São Paulo: ABRALE /HR, 2009. p.24-30.

Biopolítica: o poder médico e a autonomia do paciente em uma nova concepção de saúde. Interface - Comunic., Saude, Educ., v.8, n.14, p.21-32, 2004. Novos paradigmas e saúde. Physis, v.9, n.1, p.83-112, 1999.

QUEIROZ, M. D. S. O paradigma mecanicista da medicina ocidental moderna: uma perspectiva antropológica. Rev. Saude Publica, v.20, n.4, p.309-17, 1986.

SANTOS, L. N. "Para que servem as doenças?": Contribuições da obra de Georg Groddeck para a superação de impasses da biomedicina. Rio de Janeiro, 2012. Dissertação (Mestrado em Saúde Coletiva) - Instituto de Estudos em Saúde Coletiva, Universidade Federal do Rio de Janeiro, Rio de Janeiro. 2012.

SINGELMANN, E. A estranheza da psicanálise groddeckiana. Arq. Bras. Psicol., v.47, n.4, p.3-11, 1995.

SOUZA, M.L. Psicossomática, uma "saída" fora da estrutura. Rev. Latinoam.

Psicopatol. Fundam., v.1, n.1, p.141-50, 1997.

TESSER, C.D. Três considerações sobre a má medicina. Interface - Comunic., Saude, Educ., v.13, n.31, p.273-86, 2009.

. A verdade na biomedicina, reações adversas e efeitos colaterais: uma reflexão introdutória. Physis, v.17, n.3, p.465-84, 2007.

. Medicalização social (I): o excessivo sucesso do epistemicídio moderno na saúde. Interface - Comunic., Saude, Educ., v.10, n.19, p.61-76, 2006 a.

Medicalização social (II): limites biomédicos e propostas para a clínica na atenção básica. Interface - Comunic., Saude, Educ., v.10, n.20, p.347-62, 2006b.

WADE, D.T.; HALLIGAN, P.W. Do biomedical models of illness make for good healthcare systems? BMJ, v.329, n.7479, p.1398-401, 2004.

SANTOS, L.N.; MARTINS, A.. La originalidad de la obra de Georg Groddeck y algunas de sus contribuciones al campo de la salud . Interface - Comunic., Saude, Educ., v.17, n.44, p.9-21, jan./mar. 2013.

Este artículo tiene como objetivo presentar algunas ideas sobre la medicina, la enfermedad, la salud y la curación extraídas de la obra del médico y psicoanalista Georg Groddeck (1866-1934). La hipótesis que guía el trabajo es que tales propuestas pueden contribuir activamente a la discusión contemporánea acerca de los límites de la biomedicina y la necesidad de reformular el modelo de atención de la salud occidental. Primero, se analizan los orígenes históricos y filosóficos de la bio-medicina y algunos de los dilemas que enfrentan los usuarios y profesionales de la salud debido al predominio de la racionalidad bio-médica. A continuación se hacen algunas consideraciones sobre la vida y obra de Groddeck, culminando en la presentación de cuatro importantes contribuciones del autor evaluadas a la luz de los límites bio-médicos.

Palabras clave: Georg Groddeck. Enfermedad. Salud. Bio-medicina. 